\title{
The Numerical Simulation Analysis of Hydro Forming of Hollow Crankshaft
}

\author{
Shi Gang WANG ${ }^{1,2, a}$, Shi Ming QU' , and Shu Feng JIANG ${ }^{2}$ \\ ${ }^{1}$ School of Electrical and Information Engineering, Guangxi University of Science and Technology, 545006 Liuzhou, China \\ ${ }^{2}$ School of Mechatronics Engineering, Qiqihar University, 161006 Qiqihar, China
}

\begin{abstract}
The hydro forming process of hollow crankshaft was numerically analyzed and simulated based on Dynaform. Then the influence to hydro forming process in different loading paths was studied and the match relations between optimum forming pressure and axial feeding were obtained. The forming result was ideal and the forming parts were qualified. Finally, to the same material, the change trend of pipe billet wall thickness under the same forming pressure and axial feeding was discussed.
\end{abstract}

\section{Introduction}

With the development of aerospace industry manufacturing, the space product is gradually moving towards lightweight and improving reliability. Crankshaft is one of the important parts of aircraft engine; it has a great influence on the overall performance of the aircraft engine whose performance directly affects the service life of the aircraft [1]. In hydro forming, hollow crankshaft is used to replace the original solid crankshaft in structure, which reduces the weight of materials and makes full use of the strength and stiffness of the material [2]. Tube hydro forming technology is an advanced plastic processing technology, which is developed to form variable cross-section hollow tubular components characterized by lightweight and integration. It is a perfect combination of lightweight structure and flexible processing technology; it is also of great significance to the development of manufacturing technology of automobile, aviation, aerospace, shipbuilding and other industries [3-4].

The traditional manufacturing process of the hollow variable cross section is first stamping into two half pieces then welding them to a whole, while the hydro forming is characterized in integral forming the hollow component whose section is variable along its axis [5-6]. Compared with stamping and welding process, hydro forming has the advantages of reducing quality, saving materials, reducing the number of parts and dies, reducing the cost of making dies, reducing the amount of machining and assembling, improving the strength and rigidity, reducing the production cost and so on [7].

In this paper, the aircraft engine hollow crankshaft was numerical simulated in finite element, the hollow crankshaft hydro forming factors that influence the performance were analyzed, the distribution of wall thickness under the different conditions of hollow crankshaft forming was obtained, which has important guiding significance to the actual production.

\section{Part features and finite element model}

Aircraft engine hollow crankshaft has complex geometrical shape of non symmetry, due to the large deformation of one side and no deformation in the other; it is difficult to keep the uniformity of wall thickness in the process of forming.

In this paper, PRO/E software was used to build the geometric model, the *.IGES file format was then converted to the former processor of DYNAFORM, a finite element analysis software. In hydro forming numerical simulation, the way of mesh was commonly used shell elements, but the four nodes BT shell element was used in meshing pipe. The numerical simulation model of hollow crankshaft, as shown in Figure 1, was including modelling, pipe billet, left and right punch, pipe billet material was selected stainless steel SS304.

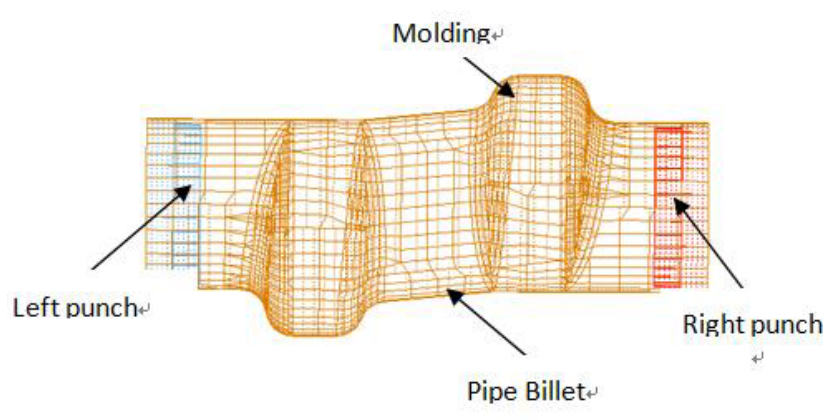

Figure 1. Numerical simulation analysis model

\footnotetext{
a Corresponding author: 446986768@qq.com
} 


\section{Simulation results analysis}

\subsection{The influence of different loading paths on the forming performance}

The shape of hollow crankshaft parts were complex, the forming was difficult, in order to obtain forming part with good uniformity of wall thickness, reasonable match of the best forming pressure and axial feeding was required. The simulation scheme was shown in Figure 2, because it is easy to implement, the 2 fold linear loading paths and 3 trapezoidal loading path were used to simulate the actual forming, the maximum plastic pressure were $70 \mathrm{MPa}, 80 \mathrm{MPa}$ and $100 \mathrm{MPa}$. The forming limit diagram (FLD), the thickness distribution and the change trend of pipe billet wall thickness as shown in Figure 3- Figure 8.

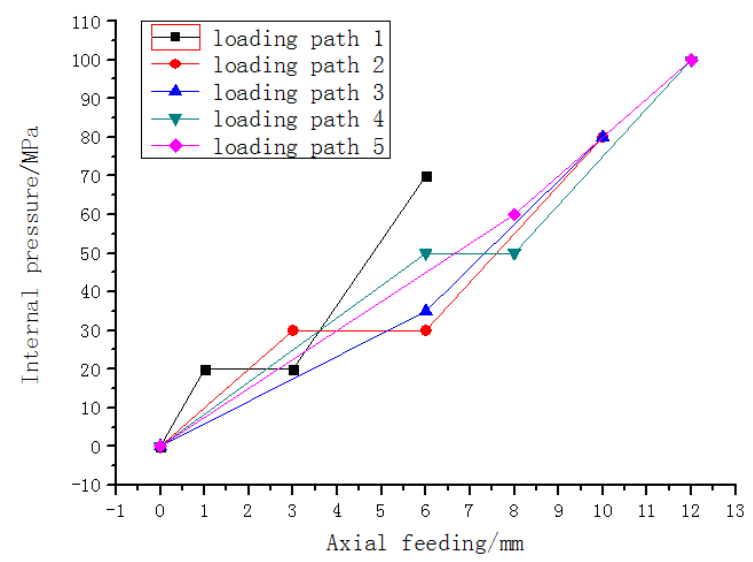

Figure 2. Five loading paths used in simulation

The internal pressure of loading path 1 was $70 \mathrm{MPa}$, the maximum axial feeding was $6 \mathrm{~mm}$, and the minimum wall thickness after forming was $2.251 \mathrm{~mm}$. But because the internal pressure was low and the forming of the curved part was not sufficient, the forming result is not obtained, the desired results have not got. The internal pressure and the axial feeding were the same in loading path 2 and the loading path 3 , but the matching relation between the internal pressure and the axial feeding was different, and the forming results were ideal. As were illustrated in Figure 8 (The Trend of Wall Thickness Changing with Loading Paths) and Figure 4 (FLD and Thickness Distribution of Loading Path 2), the forming performance of the loading path 2 was optimal, the minimum wall thickness was $2.004 \mathrm{~mm}$ and the wall thickness reduction rate was $33 \%$.

The inner pressure and the maximum feed rate of the loading path 4 and the loading path 5 are the same, but the matching relation between internal pressure and axial feeding is different. Loading paths 5 was better than loading paths 4 in formability, this was mainly due to the relationship between forming pressure and axial feeding in the early process of forming was not reasonable on loading paths 4 . Too much pressure and lack of in-time fed-batch to metal curved part made the wall thicker and thicker.

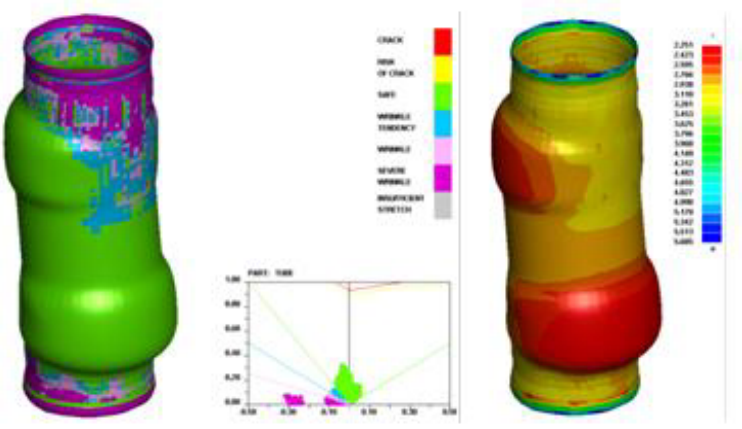

Figure 3. FLD and thickness distribution of loading path 1

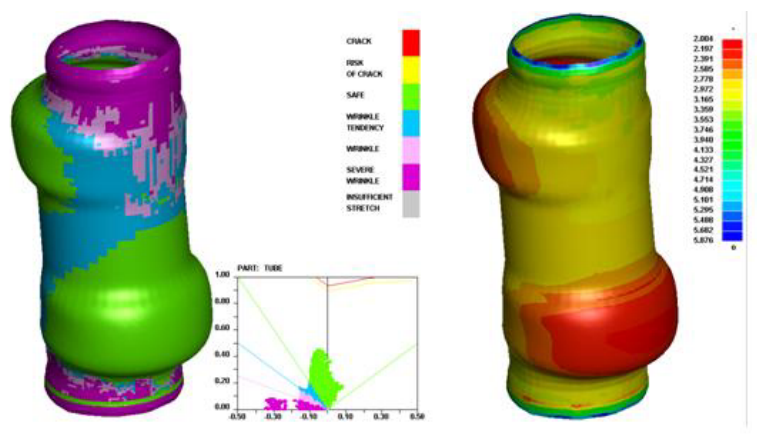

Figure 4. FLD and thickness distribution of loading path 2

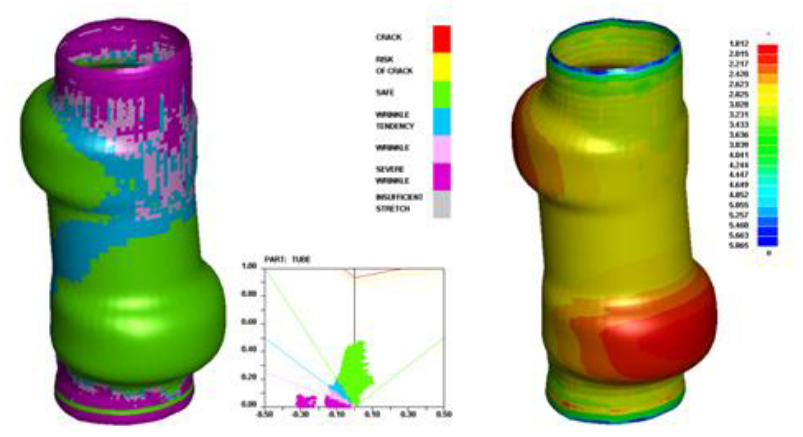

Figure 5. FLD and thickness distribution of loading path 3

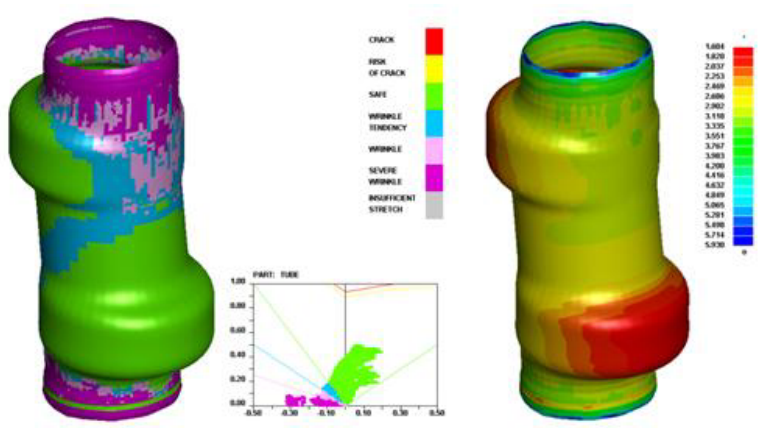

Figure 6. FLD and thickness distribution of loading path 4 


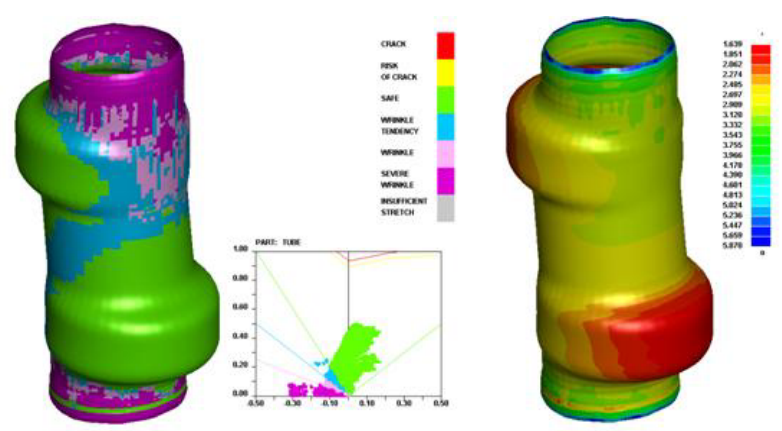

Figure 7. FLD and thickness distribution of loading path 5

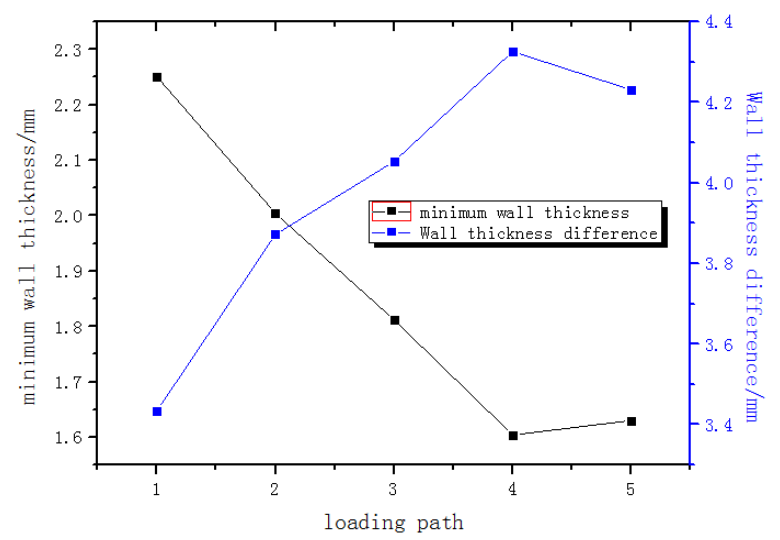

Figure 8. The trend of wall thickness changing with loading paths

\subsection{The influence of pipe billet thickness on formability}

The same material, though under the same inner pressure and axial feeding, had different forming properties of hollow crankshaft if the pipe billet thickness is different. In this paper, the thickness of tube is $2 \mathrm{~mm}, 2.5 \mathrm{~mm}, 3$ $\mathrm{mm}, 3.5 \mathrm{~mm}$ and $4 \mathrm{~mm}$, and the stainless steel SS304 was used as material. The forming results of pipe billet with different wall thickness were analyzed by the internal pressure and axial feeding in the loading path as shown in Figure 9.

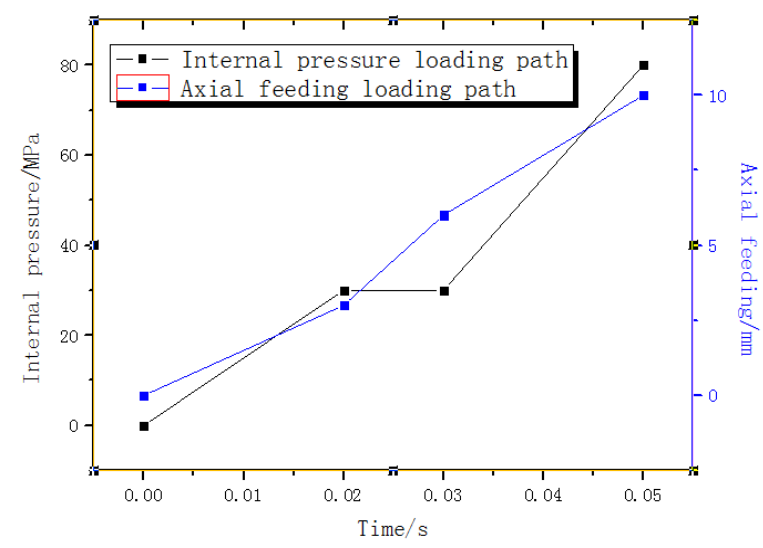

Figure 9. Pressure and axial feeding loading path
According to the parameters given in Figure 9, the wall thickness after forming changed with the thickness of the original pipe was shown in Figure 10. When the original thickness of the crankshaft is $2 \mathrm{~mm}$ and $2.5 \mathrm{~mm}$, though the formed crankshaft was not in the state of rupture, the thickness of the crankshaft was too thin which caused the poor forming performance. When the original crankshaft thickness was $3 \mathrm{~mm}$, the pipe was in the safe area, the wall thickness was uniform, and the forming performance was good. When the thickness of the original pipe was $3.5 \mathrm{~mm}$ and $4 \mathrm{~mm}$, the pipe wrinkled and was not completely affixed to the mold, so the forming quality was poor. When the inner pressure was increased, the wrinkling of the pipe can be improved. This showed that at this time the internal pressure was not up to the distortion strength of the pipe, the pipe billet had the ability to continue plastic deformation.

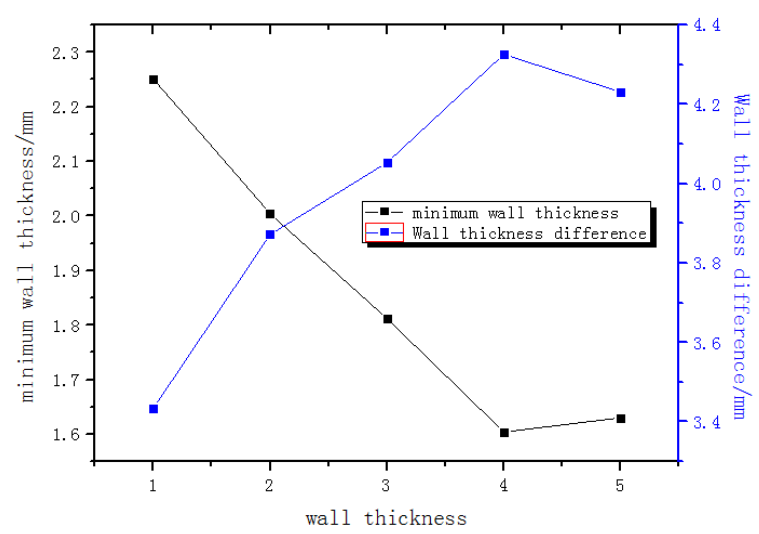

Figure 10. Wall thickness changed with the thickness of the original pipe

\section{Conclusions}

(1) The main influence factors of hollow crankshaft hydro forming are internal pressure and axial feeding. Through analyzing the forming results of five different loading paths, to get Optimum forming effect, the reasonable pressure in the hollow crankshaft should be $80 \mathrm{MPa}$, using trapezoidal loading path and the reasonable axial feeding should be $10 \mathrm{~mm}$, using fold line loading paths. After the crankshaft hydro forming, the maximum wall thickness reduction ratio is in crank, the wall thickness increases gradually extending around, and the wall thickness distribution of the opposite is on the contrary. If the internal pressure and the axial feeding rate do not match, the internal pressure increases slowly while the axial feed rate is too fast which causes the pipe billet wrinkled. When the internal pressure is too low, the forming is not sufficient and the pipe billet could not be completely affixed to the mold. When the internal pressure rising rapidly and the axial feeding rate are slow, the pipe billet fracture appears due to excessive thickness reduction.

(2) Under the same hydro forming conditions, the thicker the pipe wall, the better the forming quality. But the pipe wall is thicker, the internal pressure is greater. 
This work was supported by the Industry Project of Qiqihar City (Grant No. GYGG-201420) and Qiqihar University Graduate Innovation Research Project (Grant No. YJSCX2015030X).

\section{References}

1. Sule Feng, Biyan Zhao, Yimin Luo, Gang Liu, Zhiqiang Luo. Manufacturing Technology 5 (2014)

2. Altan T, Jirathearanat S, Strano M. Proceedings of 2nd International Conference on Hydroforming, Fellbach, Germany (2001)
3. Bing Du, Changcai Zhao, Yijiang Liu, Guojiang Dong, Pipe hydro forming model. Chinese Journal of Mechanical Engineering 16 (2014)

4. He Yang, Luoxing $\mathrm{Li}, \mathrm{Qu}$ Wang. Journal of Mechanical Engineering 12 (2010)

5. Shijian Yuan. Forging and Stamping Technology 1 (2004)

6. Junfeng Lin, Shijian Yuan. Journal of Plasticity Engineering 5 (2005)

7. Shijian Yuan, Zhubin He, Gang Liu, Xiaosong Wang, Han Cong. The Chinese Journal of Nonferrous Metals 10 (2011) 